\title{
Spotlight on solithromycin in the treatment of community-acquired bacterial pneumonia: design, development, and potential place in therapy
}

This article was published in the following Dove Press journal:

Drug Design, Development and Therapy

\author{
Bryan J Donald ${ }^{1,2}$ \\ Salim Surani ${ }^{3-5}$ \\ Harmeet S Deol',6 \\ Uche J Mbadugha' \\ George Udeani ${ }^{1,7}$ \\ 'Department of Pharmacy, Corpus \\ Christi Medical Center, Corpus \\ Christi, TX, ${ }^{2}$ Department of Clinical \\ Sciences, School of Pharmacy, \\ University of Louisiana at Monroe, \\ Monroe, LA, ${ }^{3}$ Department of \\ Pulmonology/Critical Care, Corpus \\ Christi Medical Center, Corpus \\ Christi, TX, ${ }^{4}$ Department of Medicine, \\ College of Medicine, Texas A\&M \\ University Health Science Center, \\ College Station, TX, ${ }^{5}$ Department of \\ Medicine, College of Osteopathic \\ Medicine, University of North Texas \\ Health Science Center, Denton, TX, \\ ${ }^{6}$ Department of Pharmacy Services, \\ Yale New Haven Hospital, New Haven, \\ CT, ${ }^{7}$ Pharmacy Practice, College of \\ Pharmacy, Texas A\&M University \\ Health Science Center, Kingsville, \\ TX, USA
}

\begin{abstract}
Community-acquired bacterial pneumonia (CABP) is a leading cause of death worldwide. However, antibacterial agents used to treat common pathogens in CABP are marked by adverse drug events and increasing antimicrobial resistance. Solithromycin is a new ketolide antibiotic, based on the macrolide antibiotic structure, being studied for use in CABP. It has efficacy in vitro against the common causative pathogens in CABP including Streptococcus pneumoniae, Haemophilus influenzae, and atypical pathogens. In Phase II and Phase III clinical trials, it has been demonstrated efficacious as a single agent for treatment of CABP with an apparently milder adverse event profile than alternative agents.
\end{abstract}

Keywords: solithromycin, macrolide antibiotics, community-acquired bacterial pneumonia, CABP

\section{Introduction}

Community-acquired bacterial pneumonia (CABP) is a lower respiratory tract infection acquired anywhere other than an acute care (hospital) or long-term care (nursing facility) setting. ${ }^{1}$ In the USA alone, CABP may affect over 5 million patients and cause over 60,000 deaths annually. ${ }^{2,3}$ Worldwide, lower respiratory tract infections may be responsible for nearly 3 million deaths annually. ${ }^{4}$ Patients $\geq 65$ years and patients $<5$ years have a higher incidence of pneumonia, but pneumonia may affect patients of any age. ${ }^{5}$ The most common causes of CABP are Streptococcus pneumoniae (pneumococcus), Haemophilus influenzae, and in some regions, atypical pathogens including Legionella, Mycoplasma, and Chlamydia species. Other pathogens, including Mycoplasma and Gram-negative bacilli, may also be involved. ${ }^{1,46}$ Empiric recommendations are based on historical data and focus is on macrolide, fluoroquinolone, and beta-lactam antibiotics alone or in combination. ${ }^{1}$ The high relative mortality of infections such as pneumonia coupled with problems with multi-drug resistant organisms, including macrolide-resistant $S$. pneumoniae, have prompted international calls for the design and development of novel antimicrobial agents. ${ }^{7-9}$

Solithromycin is a fluoroketolide "fourth-generation" macrolide antibiotic designed by Cempra ${ }^{\circledR}$, Inc (Chapel Hill, NC, USA). Phase II and III trials have been conducted assessing solithromycin for use in CAPB and uncomplicated gonorrhea with promising results. ${ }^{10-13}$ The highlights of solithromycin use in CABP include 1) activity against the common agents S. pneumoniae, $H$. influenzae, and atypical pathogens, including those resistant to other macrolide antibiotics, 2) non-inferiority when compared to the respiratory fluoroquinolone antibiotic moxifloxacin in two Phase III trials, 3) an adverse
Correspondence: Bryan J Donald Department of Clinical Sciences, School of Pharmacy, University of Louisiana Monroe, I800 Bienville Dr, Monroe LA 7II20I, USA

$\mathrm{Tel}+\mathrm{I} 3183421903$

Email donald@ulm.edu 
event profile milder than that of other macrolide antibiotics, and 4) no association with Clostridium difficile infection as commonly seen with fluoroquinolones and many betalactam antibiotics. ${ }^{8,10,11,14,15}$ Although solithromycin has been examined for potential uses in uncomplicated gonorrhea, Mycoplasma genitalium infections, bacterial infections in pregnancy, non-alcoholic fatty liver disease, and COPD, these uses are outside the scope of this review..$^{12,16-19}$

\section{Design and development}

The first macrolide antibiotic, erythromycin (Figure 1), was first released in 1954. It is associated with multiple adverse effects: diarrhea, hepatic dysfunction, QT prolongation, multiple drug interactions, and increasing resistance in target pathogens. ${ }^{14,20,21}$ Azithromycin (Figure 2) was approved by the US Food and Drug Administration (FDA) in 1991 and has become a mainstay of outpatient therapy for respiratory infections, although its over- and under-use have been associated with emerging resistance. Azithromycin is also associated with hepatotoxicity, QT prolongation, and $C$. difficile infections, and carries a warning concerning exacerbation of myasthenia gravis symptoms. However, it does not appear to inhibit CYP3A4 and it does not carry as many interactions as other macrolide antibiotics. ${ }^{14,16,22}$ Telithromycin (Figure 3) is the first ketolide antibiotic and was approved in Europe in 2001 and in America in 2004. The new ketolide was expected to overcome macrolide resistance by improving the strength of binding to $23 \mathrm{~S}$ ribosomal RNA domain II while retaining binding to domain $\mathrm{V}$ (macrolides bind strongly to domain $\mathrm{V}$ and weakly to domain II); telithromycin is also considered bactericidal, where macrolides are considered bacteriostatic..$^{8,14,23,24}$ Concerns over hepatotoxicity resulted

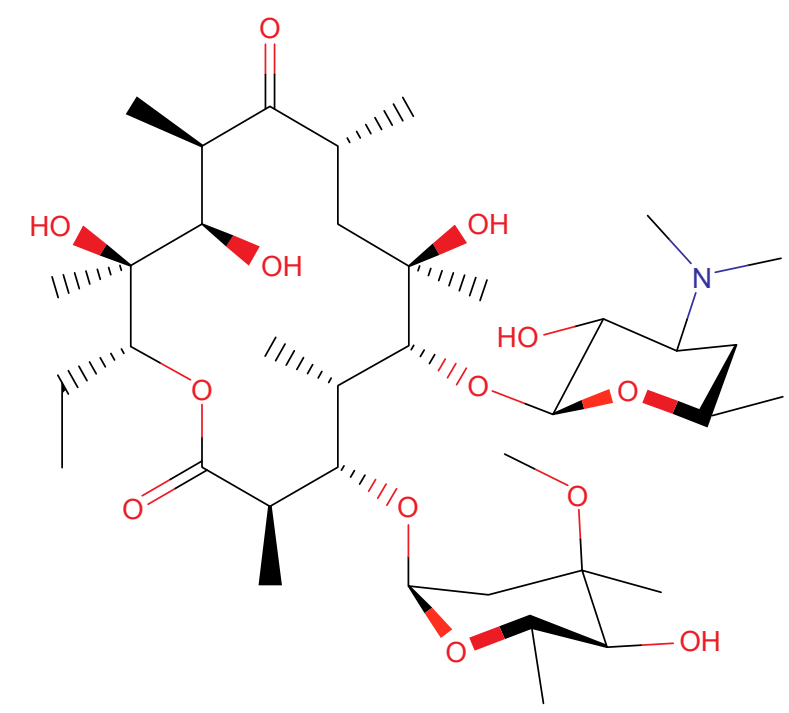

Figure I Erythromycin, a first-generation macrolide antibiotic.

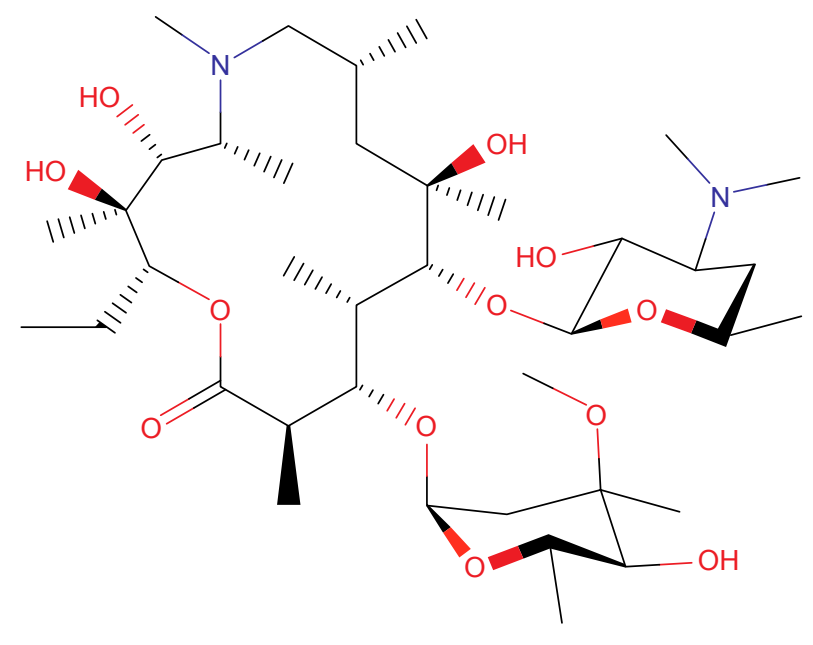

Figure 2 Azithromycin, a second-generation macrolide antibiotic.

in an additional labeled warning for telithromycin in 2006, and the indications for acute bacterial sinusitis and acute bacterial exacerbations of chronic bronchitis were removed in 2007, with a new boxed warning for patients with myasthenia gravis. ${ }^{25-27}$ Because of these and other adverse events, telithromycin is no longer actively marketed, underscoring the need for a new, tolerable antibiotic with bactericidal activity against macrolide-resistant organisms. ${ }^{14,28}$

Solithromycin's structure helps to overcome macrolide resistance as well as overcome problems with adverse events of telithromycin (Figure 4). Key elements of solithromycin activity are described in Table 1 and include resistance to induction of macrolide-lincosamide-streptogramin B (MLSB)-mediated modifications (shared with telithromycin), resistance to modifications in the domain $\mathrm{V}$ binding site (shared with telithromycin), improved hydrogen binding at the domain II binding site (similar to telithromycin), and a third 23S ribosomal RNA binding site accomplished by the

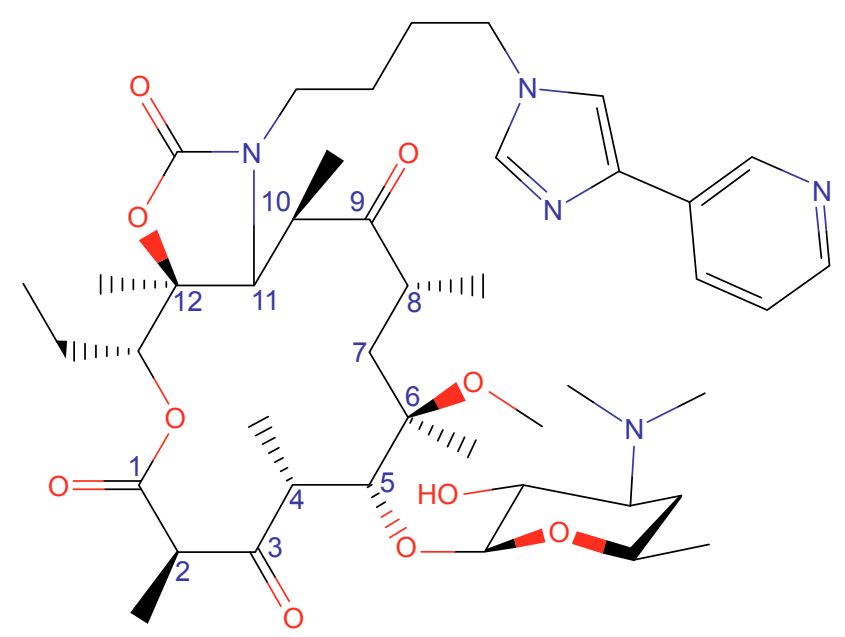

Figure 3 Telithromycin, a third-generation macrolide or ketolide antibiotic. 


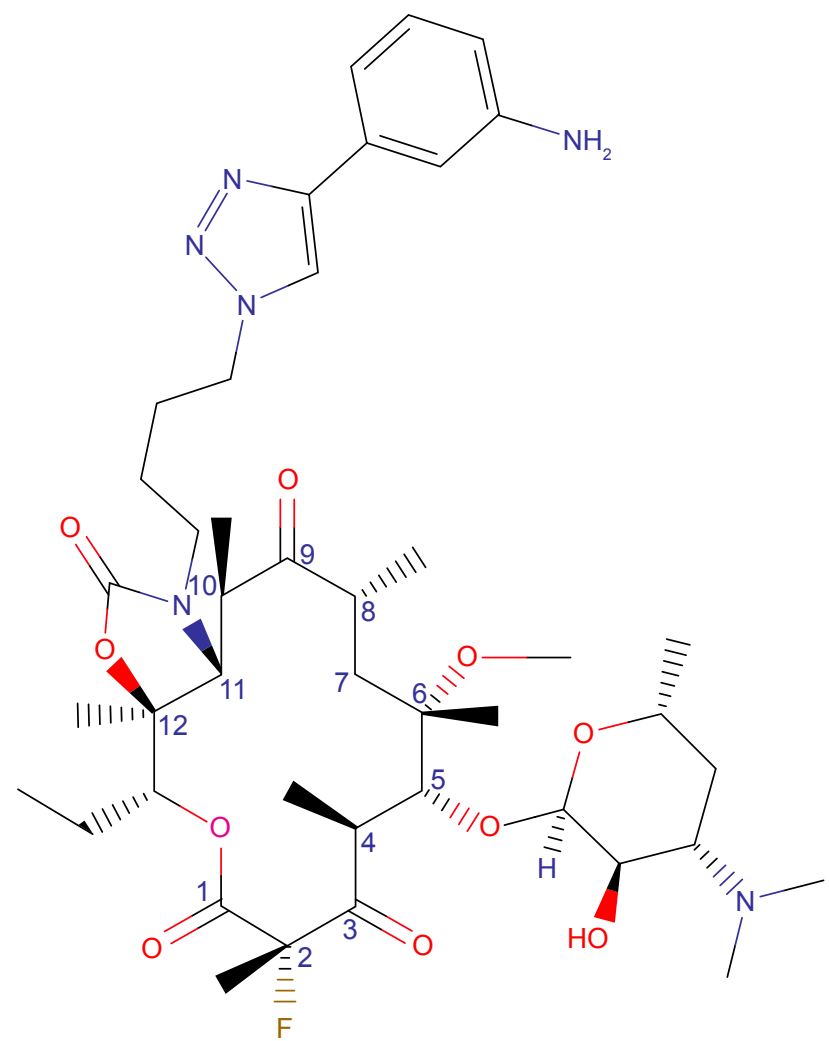

Figure 4 Solithromycin, a fourth-generation macrolide or fluoroketolide antibiotic.

C2 fluorine (unique to solithromycin). ${ }^{9,14,29,30}$ Solithromycin also lacks the pyridine moiety presumed to be associated with telithromycin-induced liver injury. ${ }^{31}$ In short, the highlights of the differences between solithromycin and telithromycin include the aromatic side chain with an aminophenyl group allowing for a third binding site, compared with two for telithromycin, the lack of a pyridine moiety, presumably reducing hepatic toxicity, and the presence of a fluorine at $\mathrm{C}-2$, improving drug binding and enhancing activity.

\section{Microbiology}

\section{Mechanisms of action and resistance}

As with macrolides, solithromycin works by binding to the 50S ribosomal subunit near the peptide exit tunnel, resulting

Table I Key structures affecting solithromycin activity

\begin{tabular}{|c|c|c|}
\hline Structure & Position & Activity \\
\hline $\begin{array}{l}\text { Ketone (lack of } \\
\text { cladinose group) }\end{array}$ & $\mathrm{C} 3$ & $\begin{array}{l}\text { Resistance to inducible MLSB target } \\
\text { modification } \\
\text { Removal of steric hindrance with } \\
\text { methylated S } 23 \text { domain V binding site }\end{array}$ \\
\hline $\begin{array}{l}\text { Aromatic side } \\
\text { chain }\end{array}$ & $\mathrm{ClI}, \mathrm{I} 2$ & $\begin{array}{l}\text { Hydrogen bond acceptor for binding } \\
\text { site at S23 domain II }\end{array}$ \\
\hline Fluorine & $\mathrm{C} 2$ & $\begin{array}{l}\text { Third binding site to } 23 \mathrm{~S} \text { rRNA } \\
\text { Prevents enolization of } \mathrm{C} 3 \text { ketone }\end{array}$ \\
\hline
\end{tabular}

Note: Data from Van Bambeke', Fernandes et al ${ }^{14}$, Llano-Satelo et $\mathrm{al}^{29}$, Juda et $\mathrm{a}^{30}$, and Bertrand et al. ${ }^{31}$

Abbreviation: MLSB, macrolide-lincosamide-streptogramin B. in premature termination of translation and frame shift errors in translation. ${ }^{29}$ This mechanism is usually considered bacteriostatic, but ketolides are considered bactericidal, possibly due to their added ability to interfere with formation of the ribosomal $50 \mathrm{~S}$ unit. ${ }^{23,32}$

Usual mechanisms of resistance involve modifying the target binding site (erythromycin ribosomal methylation) and efflux of the macrolide (macrolide efflux). ${ }^{30}$

Erythromycin ribosomal methylation, erm, is the most common mechanism of resistance for MLSB organisms. Macrolides are further known to induce methylation in MLSB organisms, a mechanism known as inducible MLSB (iMLSB) as opposed to constitutive MLSB (cMLSB) where rRNA methylase is always produced. ${ }^{30,33}$ Solithromycin does not trigger iMLSB-mediated rRNA methylation and is still active against cMLSB organisms due to its third binding site and C3 ketone group. ${ }^{14,29}$

Macrolide efflux, mef, is an efflux pump for macrolides. Ketolides have been found to be less sensitive to mef, which may contribute to solithromycin's restored activity against $H$. influenzae, but may require higher concentrations to remain efficacious. ${ }^{34}$

L4/L22 mutations are rare modifications to ribosomal proteins which may confer solithromycin resistance. However, even with these phenotypes included, solithromycin performed well on resistance selection studies; so development of resistance may not be significant and will have to be determined clinically. ${ }^{35}$

\section{In vitro activity}

Solithromycin has demonstrated in vitro efficacy against a wide variety of Gram-positive, Gram-negative, and atypical organisms known to cause pneumonia (Table 2). ${ }^{10-13,16,17,32,36-43}$ Although clinical correlation is not complete, solithromycin appears to have a similar spectrum of activity to telithromycin and even some activity against telithromycin-resistant organisms. Highlights of solithromycin's antibacterial activity include S. pneumoniae (especially macrolide-, penicillin-, and fluoroquinolone-resistant strains), H. influenzae, and pneumonia-causing atypical pathogens.

\section{Pharmacokinetics and pharmacodynamics}

Solithromycin is both a substrate and an inhibitor of cytochrome P450 CYP 3A4. As it autoinhibits its own clearance, solithromycin half-life extends with higher and cumulative doses, similar to macrolides: 7 days of $400 \mathrm{mg}$ solithromycin per day yields half-lives ranging from 4.8 to 7.5 h. ${ }^{44-46}$ Because solithromycin's major metabolic pathway involves CYP 3A4, it is likely to be subject to the same or 
Table 2 Susceptible organisms from in vitro and limited clinical data

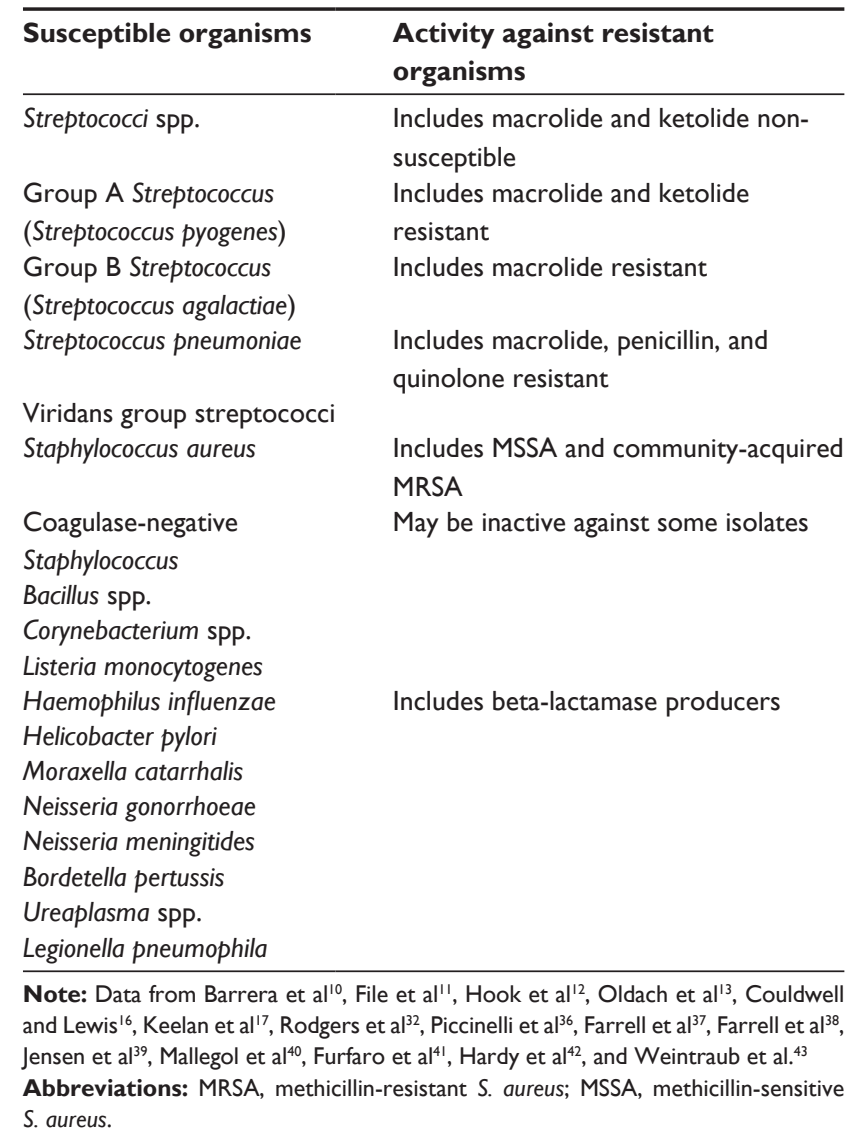

similar drug interactions as erythromycin, clarithromycin, and telithromycin, but not azithromycin, which has a different metabolic pathway. ${ }^{20,22,24,45}$ Due to an uncertain mechanism, possibly uptake of the drug by polymorphonuclear neutrophils (PMNs), solithromycin achieves higher concentrations in epithelial lining fluid and alveolar macrophages than in plasma; this is similar to macrolides and other ketolides and may contribute to solithromycin's utility in treating CABP. ${ }^{47}$ Finally, solithromycin was studied in patients with mild, moderate, and severe chronic liver disease: renal excretion remained $5 \%-10 \%$, indicating that renal dose reductions are not likely necessary, and no dose reduction was recommended for patients with chronic liver disease, although area under the curve (AUC) was lower in severe liver disease, possibly due to an expanded volume of distribution in these patients. ${ }^{44}$

\section{Clinical trials}

Phase II trial

A Phase II, randomized, double-blind, controlled trial was conducted comparing 5 days of solithromycin $(800 \mathrm{mg}$ once on day $1,400 \mathrm{mg}$ once daily thereafter) to 5 days of levofloxacin (750 $\mathrm{mg}$ once daily) in patients with CABP.
Patients had to be $\geq 18$ years and with symptomatic pneumonia (pneumonia severity index score $>50$ and $\leq 150$ ) defined as three factors: cough with production of purulent sputum or a change in the character of sputum consistent with bacterial infection, dyspnea, or tachypnea; chest pain consistent with pneumonia; fever, rales, or radiographic evidence of consolidation. Patients were excluded if they received prior antimicrobial therapy (excepting documented treatment failure after $48 \mathrm{~h}$ ), had known bronchial obstruction not related to pneumonia, or stage IV COPD, among other safety-related exclusions. Levofloxacin was chosen for its place in US guidelines as monotherapy for CABP.

Patients were analyzed in four populations: 1) intentionto-treat (ITT) for all randomized patients, 2) clinically evaluable (CE) for patients who received at least two doses of the study drug (within $48 \mathrm{~h}$ ) with clinical failure or at least four doses of the study drug with clinical success, 3) microbiological ITT (micro-ITT) as ITT patients with an identified bacterial pathogen associated with $\mathrm{CABP}$, and 4) microbiologically evaluable (ME) as CE patients with an identified bacterial pathogen associated with CABP. The safety analysis included all patients who received at least one dose of the study drug. The primary endpoint was clinical success at test of cure (TOC) 4-11 days after last dose of study drug defined as: complete or nearly complete resolution of baseline symptoms, no new CABP symptoms, and radiologic resolution, improvement, or stability. An early clinical response was added to comply with FDA and Foundation for the National Institutes of Health (FNIH) expectations, and required improvement in symptoms at day 3 .

The study was not powered for inferential statistics, but efficacy outcomes were similar for both solithromycin and levofloxacin. In the safety analysis, gastrointestinal disorders were the most common adverse events for both groups. No patients withdrew from the solithromycin group due to adverse events, compared with six patients from the levofloxacin group, but the study was not powered for inferential statistics. No patients in the solithromycin group reported nervous system or psychiatric disorders, compared with three patients from the levofloxacin group, and no patients in the solithromycin group showed elevated alanine aminotransferase (ALT) or aspartate aminotransferase (AST) levels. The authors concluded that solithromycin had efficacy comparable to levofloxacin with a favorable adverse event profile. ${ }^{13}$

\section{SOLITAIRE-ORAL}

SOLITAIRE-ORAL was a Phase III, global, randomized, double-blind, controlled, non-inferiority trial comparing 
the same 5-day regimen of solithromycin to 7 days of moxifloxacin $400 \mathrm{mg}$ once daily. Inclusion and exclusion criteria were similar to the Phase II trial except for changes made to comply with newer FDA expectations for such a trial, such as symptom inclusion criteria. The inclusion of Pneumonia Patient Outcomes Research Team score 2 (PORT 2) pneumonia patients was capped to ensure adequate inclusion of moderately severe patients (PORT 2 describes low risk for morbidity and mortality associated with CABP, compared to PORT 3 and 4, which describe moderate and high risk). Moxifloxacin was chosen as a comparator for its place in the guidelines as monotherapy and similar spectrum of activity to solithromycin.

Early clinical response was chosen as the primary outcome and defined as improvement in at least two cardinal symptoms (cough, chest pain, sputum production, dyspnea) and no worsening in any symptom at $72 \mathrm{~h}$ (evaluated at 71 to $108 \mathrm{~h}$ ) after the first dose of the study drug. Clinical success at TOC visit was maintained as a secondary outcome to comply with European Medicines Agency expectations. For SOLITAIRE-ORAL, the CE population was defined as per-protocol, and a second microbiological ITT (mITT-2) population was limited to positive cultures from blood, pleural fluid, sputum, oropharyngeal Mycoplasma pneumoniae swab, or urine Legionella antigen.

Early clinical response in the ITT population was observed in 333/426 (78.2\%) patients in the solithromycin group and $338 / 434(77.9 \%)$ patients in the moxifloxacin group (difference $0.29 \%, 95 \% \mathrm{CI}-5.5$ to 6.1 ), meeting the pre-specified cutoff for non-inferiority. Early clinical response in the CE population also showed non-inferiority (solithromycin 326 [80.9\%], moxifloxacin 330 [81.1\%], difference $-0.19,95 \%$ $\mathrm{CI}-5.8$ to 5.5$)$. Non-inferiority was demonstrated at shortterm follow-up also. As with the Phase II trial, the most common isolates in the microbiological populations were S. pneumoniae (including macrolide-resistant S. pneumoniae), H. influenzae, M. pneumoniae, and Legionella.

Forty-three $(10 \%)$ patients in the solithromycin group and $54(13 \%)$ in the moxifloxacin group experienced adverse events related to study treatment. Serious adverse events and discontinuations due to adverse events were similar in both groups. Two patients in the moxifloxacin group were found to have $C$. difficile associated diarrhea, compared with none in the solithromycin group, but this was not a pre-specified endpoint and not routinely tested. No patients experienced serious cardiovascular events attributed to the study drug or developed hepatobiliary abnormalities meeting Hy's law, defined as ALT or AST greater than three times upper limit of normal, alkaline phosphatase less than two times upper limit of normal, and total bilirubin greater than two times upper limit of normal, without alternate explanation. ${ }^{10}$ The study did report the rates of aminotransferase elevations: ALT was elevated greater than three times upper limit of normal in $22(5.4 \%)$ patients receiving solithromycin and only in 14 (3.3\%) patients receiving moxifloxacin; AST was elevated greater than three times upper limit of normal in $10(2.5 \%)$ patients receiving solithromycin compared to $8(1.9 \%)$ patients receiving moxifloxacin.

The study authors concluded that solithromycin was non-inferior to moxifloxacin for CABP without an increase in adverse events, and with a lower risk for precipitating C. difficile colitis. They did voice a desire to extend follow-up to measure the effect of CABP on long-term outcomes. ${ }^{10}$

\section{SOLITAIRE-IV}

SOLITAIRE-IV was a Phase III, randomized, double-blind, controlled study comparing solithromycin to moxifloxacin. In this trial, the study drug was initially delivered via the intravenous (IV) route, and prescribers had the option to switch to oral (PO) therapy based on pre-defined IV-to-PO criteria. IV doses for both drugs were $400 \mathrm{mg}$ once daily; PO therapy was the same as in SOLITAIRE-ORAL, including the $800 \mathrm{mg}$ loading dose given as the first PO dose. Therapy continued for a total of 7 days, regardless of when, or if, an IV-to-PO conversion was performed. Inclusion and exclusion criteria were similar to SOLITAIRE-ORAL.

Early clinical response was the primary endpoint for SOLITAIRE-IV, with end of treatment, short-term follow-up, and late follow-up evaluations as secondary endpoints. Analysis populations were defined as in SOLITAIRE-ORAL. For the ITT population, early clinical response was achieved in 344/434 (79.3\%) patients in the solithromycin group and in $342 / 429(79.7 \%)$ patients in the moxifloxacin group (difference $-0.46,95 \% \mathrm{CI}-6.1$ to 5.2 ), meeting the criteria for non-inferiority. Mean duration of IV treatment was the same in both groups.

Infusion reactions were much more common in the solithromycin group (31.3\%) compared to the moxifloxacin group (5.4\%). Adverse events not related to infusion reactions were similar for both groups. Solithromycin was associated with elevations in ALT and AST, but these were asymptomatic and generally resolved by short-term follow-up. The study authors' discussion recognized the increases in hepatic aminotransferase levels and increased incidence of infusion site reactions, which are common with macrolide antibiotics, and maintained, as with SOLITAIRE-ORAL, 
that solithromycin is non-inferior to moxifloxacin for the treatment of CABP regardless of dose formulation. ${ }^{11}$

\section{Additional safety trials}

The Phase II and Phase III trials for solithromycin did not report QT intervals associated with solithromycin as an outcome. Macrolide antibiotics have been known to prolong QTc, making this an important safety endpoint for the new fluoroketolide. A specially conducted, randomized, crossover, double-blind trial assessed the effects of placebo, solithromycin, and moxifloxacin on echocardiography. Using a difference of $10 \mathrm{~ms}$ as a cutoff, the study concluded that solithromycin, unlike macrolide antibiotics, does not prolong QTc. ${ }^{48}$

A Phase I trial was performed examining the use and pharmacokinetics of solithromycin in adolescents. Thirteen adolescents, aged 12-17, were given solithromycin in addition to appropriate antimicrobial therapy for suspected or known infections. The authors concluded that kinetics in adolescents was similar to healthy adults, but the sample size was small and confounded by disease state (cystic fibrosis), concurrent therapy with CYP 3A4 inducers, and one blood transfusion. Two adolescents experienced mild headaches and one displayed elevated transaminase levels less than three times upper limit of normal, but this patient was on other medications known to raise transaminase levels. A Phase II trial will be needed to further characterize the utility of solithromycin for CABP in children and adolescents. $^{49}$

\section{Discussion}

In light of the incidence of CABP, the mortality rate associated with pneumonia, and the increasing antimicrobial resistance in organisms most commonly seen in CABP, solithromycin is a promising new drug. It has increased activity against common CABP organisms compared to both macrolide and ketolide antibiotics, and an apparent adverse event profile which is much safer than that of the only currently FDA-approved ketolide antibiotic, and both of these traits are supported by solithromycin's medicinal chemistry. It is easy to use for outpatient treatment, and the dosing regimen is similar to azithromycin; so its proper use will be familiar to many healthcare providers. In addition, solithromycin does not carry warnings against $C$. difficile colitis or tendon rupture associated with fluoroquinolones, both of which may be magnified in elderly patients who are more likely to need treatment for pneumonia, and it has a spectrum of activity, which includes likely pathogens, unlike beta-lactam antibiotics.

\section{FDA response letter}

On December 29, 2016, the FDA released its complete response letter (CRL) to Cempra, Inc., regarding their new drug application for solithromycin. The CRL states that $<1,000$ patients treated with solithromycin in their submitted studies is too few to adequately characterize the risk of hepatic adverse events or a possible relationship to drug-induced liver injury. The FDA is asking for a study of 9,000 patients to better characterize the risk, and also suggests that even if no serious adverse events are found, the labeling will not only contain warnings about potential hepatotoxicity, but require that solithromycin be used only in patients who have limited therapeutic options. ${ }^{50}$ This may be concerning to some who think the FDA is being too strict with novel antibiotics and see this as a problem when combating drug-resistant organisms. ${ }^{28}$ While limiting use of a novel antibiotic may be useful from an antimicrobial stewardship perspective, it might also be premature to require specific labeling before collecting adequate information to characterize the risk. Either way, azithromycin carries a label warning for hepatotoxicity, which has not curtailed its use, and the strength of a comparison between solithromycin and telithromycin from a safety perspective will increase after the larger trial is conducted and reported.

\section{Potential place in therapy}

Solithromycin is a novel antimicrobial with bactericidal activity against the most common pathogens associated with $\mathrm{CABP}$, useful in both outpatient and inpatient settings, and subject to few effective mechanisms for resistance. If safety concerns about solithromycin and hepatotoxicity can be resolved, solithromycin may find a place as a first-line therapy for $\mathrm{CABP}$ or as a second-line therapy for patients who fail to show early clinical response to other first-line therapies.

\section{Disclosure}

The authors report no conflicts of interest in this work.

\section{References}

1. Mandell LA, Wunderink RG, Anzueto A, et al; American Thoracic Society. Infectious Diseases Society of America/American Thoracic Society consensus guidelines on the management of community-acquired pneumonia in adults. Clin Infect Dis. 2007;44(Suppl 2):S27-S72.

2. Brar NK, Niederman MS. Management of community-acquired pneumonia: a review and update. Ther Adv Respir Dis. 2011;5(1):61-78 
3. Kaysin A, Viera AJ. Community-acquired pneumonia in adults: diagnosis and management. Am Fam Physician. 2016;94(9):698-706.

4. GBD 2015 Mortality and Causes of Death Collaborators. Global, regional, and national life expectancy, all-cause mortality, and causespecific mortality for 249 causes of death, 1980-2015: a systematic analysis for the Global Burden of Disease Study 2015. Lancet. 2016; 388(10053):1459-1544.

5. Broulette J, Yu H, Pyenson B, Iwasaki K, Sato R. The incidence rate and economic burden of community-acquired pneumonia in a working-age population. Am Heal Drug Benefits. 2013;6(8):494-503.

6. Niederman MS, Luna CM. Community-acquired pneumonia guidelines: a global perspective. Semin Respir Crit Care Med. 2012;33(3): 298-310.

7. Boucher HW, Talbot GH, Bradley JS, et al. Bad bugs, no drugs: no ESKAPE! An update from the Infectious Diseases Society of America. Clin Infect Dis. 2009;48(1):1-12.

8. Farrell DJ, Flamm RK, Sader HS, Jones RN. Results from the Solithromycin International Surveillance Program (2014). Antimicrob Agents Chemother. 2016;60(6):3662-3668.

9. Van Bambeke F. Renaissance of antibiotics against difficult infections: focus on oritavancin and new ketolides and quinolones. Ann Med. 2014;46(7):512-529.

10. Barrera CM, Mykietiuk A, Metev H, et al; SOLITAIRE-ORAL Pneumonia Team. Efficacy and safety of oral solithromycin versus oral moxifloxacin for treatment of community-acquired bacterial pneumonia: a global, double-blind, multicentre, randomised, active-controlled, non-inferiority trial (SOLITAIRE-ORAL). Lancet Infect Dis. 2016;16(4):421-430.

11. File TM Jr, Rewerska B, Vucinic-Mihailovic V, et al. SOLITAIRE-IV: A Randomized, Double-Blind, Multicenter Study comparing the efficacy and safety of intravenous-to-oral solithromycin to intravenousto-oral moxifloxacin for treatment of community-acquired bacterial pneumonia. Clin Infect Dis. 2016;63(8):1007-1016.

12. Hook EW 3rd, Golden M, Jamieson BD, et al. A phase 2 trial of oral solithromycin $1200 \mathrm{mg}$ or $1000 \mathrm{mg}$ as single-dose oral therapy for uncomplicated gonorrhea. Clin Infect Dis. 2015;61(7):1043-1048.

13. Oldach D, Clark K, Schranz J, et al. Randomized, Double-Blind, Multicenter Phase 2 Study comparing the efficacy and safety of oral solithromycin (CEM-101) to those of oral levofloxacin in the treatment of patients with community-acquired bacterial pneumonia. Antimicrob Agents Chemother. 2013;57(6):2526-2534.

14. Fernandes P, Martens E, Bertrand D, Pereira D. The solithromycin journey - it is all in the chemistry. Bioorg Med Chem. 2016;24(24): 6420-6428.

15. Communication FDS. FDA Drug Safety Communication: FDA advises restricting fluoroquinolone antibiotic use for certain uncomplicated infections; warns about disabling side effects that can occur together. Available from: https://www.fda.gov/Drugs/DrugSafety/ucm500143. htm. Published 2016. Accessed January 31, 2017.

16. Couldwell DL, Lewis DA. Mycoplasma genitalium infection: current treatment options, therapeutic failure, and resistance-associated mutations. Infect Drug Resist. 2015;8:147-161.

17. Keelan JA, Payne MS, Kemp MW, Ireland DJ, Newnham JP. A new, potent, and placenta-permeable macrolide antibiotic, solithromycin, for the prevention and treatment of bacterial infections in pregnancy. Front Immunol. 2016;7:111.

18. Rotman Y, Sanyal AJ. Current and upcoming pharmacotherapy for non-alcoholic fatty liver disease. Gut. 2017;66(1):180-190.

19. Kobayashi Y, Wada H, Rossios C, et al. A novel macrolide solithromycin exerts superior anti-inflammatory effect via NF-kB inhibition. J Pharmacol Exp Ther. 2013;345(1):76-84.

20. ANI Pharmaceuticals. Erythromycin ethylsuccinate - erythromycin ethylsuccinate granule, for suspension. [Updated Sept 27, 2016]. In: DailyMed [homepage on the Internet]. Bethesda MD, US: National Library of Medicine. Available from: https://dailymed.nlm.nih.gov/dailymed/drugInfo.cfm?setid=3de1e0b9-473b-44c0-a644-5fa14ad69a83. Accessed October 9, 2017.
21. Camilleri M, Parkman HP, Shafi MA, Abell TL, Gerson L. Clinical guideline: management of gastroparesis. Am J Gastroenterol. 2013; 108(1):18-38.

22. Pfizer Laboratories Div Phizer Inc. Zithromax - azithromycin dihydrate tablet, film coated; Zithromax - azithromycin dihydrate powder, for suspension. [Updated May 18, 2017]. In: DailyMed [Internet]. Bethesda MD, US: National Library of Medicine. Available from: https:// dailymed.nlm.nih.gov/dailymed/drugInfo.cfm?setid=db52b91e-79f74cc1-9564-f2eee8e31c45. Accessed October 9, 2017.

23. Shi J, Montay G, Bhargava VO. Clinical pharmacokinetics of telithromycin, the first ketolide antibacterial. Clin Pharmacokinet. 2005;44(9): 915-934.

24. Sanofi-Aventis U.S. LLC. Ketek - telithromycin tablet, film-coated. [Updated May 2, 2012]. In: DailyMed [Internet]. Bethesda MD, US: National Library of Medicine. Available from: https://dailymed.nlm. nih.gov/dailymed/drugInfo.cfm?setid=ba1cca98-f350-4655-88e3-6ef990779fb9. Accessed October 9, 2017.

25. Clay KD, Hanson JS, Pope SD, Rissmiller RW, Purdum PP 3rd, Banks PM. Brief communication: severe hepatotoxicity of telithromycin: three case reports and literature review. Ann Intern Med. 2006;144(6):415-420.

26. FDA News Releases. FDA completes safety assessment of Ketek new safety information to be added to product labeling. Available from: https:// www.fda.gov/NewsEvents/Newsroom/PressAnnouncements/2006/ ucm108682.htm. Published 2006. Accessed January 7, 2017.

27. FDA News Releases. FDA announces label and indication changes for the antibiotic Ketek. Available from: https://www.fda.gov/NewsEvents/ Newsroom/PressAnnouncements/2007/ucm108842.htm. Published 2007. Accessed January 7, 2017.

28. Jarvis LM. The Ketek Effect: biotechs worry that FDA has gotten tougher on approving new antibiotics. Chem Eng News. Available from: http://cen.acs.org/articles/86/i15/Ketek-Effect.html. Published 2008. Accessed January 4, 2017.

29. Llano-Sotelo B, Dunkle J, Klepacki D, et al. Binding and action of CEM-101, a new fluoroketolide antibiotic that inhibits protein synthesis. Antimicrob Agents Chemother. 2010;54(12):4961-4970.

30. Juda M, Chudzik-Rzad B, Malm A. The prevalence of genotypes that determine resistance to macrolides, lincosamides, and streptogramins B compared with spiramycin susceptibility among erythromycin-resistant Staphylococcus epidermidis. Mem Inst Oswaldo Cruz. 2016;111(3): 155-160.

31. Bertrand D, Bertrand S, Neveu E, Fernandes P. Molecular characterization of off-target activities of telithromycin: a potential role for nicotinic acetylcholine receptors. Antimicrob Agents Chemother. 2010;54(12):5399-5402.

32. Rodgers W, Frazier AD, Champney WS. Solithromycin inhibition of protein synthesis and ribosome biogenesis in Staphylococcus aureus, Streptococcus pneumoniae, and Haemophilus influenzae. Antimicrob Agents Chemother. 2013;57(4):1632-1637.

33. Saderi H, Emadi B, Owlia P. Phenotypic and genotypic study of macrolide, lincosamide and streptogramin B (MLS B) resistance in clinical isolates of Staphylococcus aureus in Tehran, Iran. Med Sci Monit. 2011;17(2):BR48-BR53.

34. Sutcliffe JA. Antibiotics in development targeting protein synthesis. Ann N Y Acad Sci. 2011;1241:122-152.

35. Mcghee P, Clark C, Kosowska-shick KM, et al. In vitro activity of CEM-101 against Streptococcus pneumoniae and Streptococcus pyogenes with defined macrolide resistance mechanisms. Antimicrob Agents Chemother. 2010;54(1):230-238.

36. Piccinelli G, Fernandes P, Bonfanti C, Caccuri F, Caruso A, De Francesco MA. In vitro activity of solithromycin against erythromycinresistant Streptococcus agalactiae. Antimicrob Agents Chemother. 2014;58(3):1693-1698.

37. Farrell DJ, Mendes RE, Jones RN. Antimicrobial activity of solithromycin against serotyped macrolide-resistant Streptococcus pneumoniae isolates collected from U.S. medical centers in 2012. Antimicrob Agents Chemother. 2015;59(4):2432-2434. 
38. Farrell DJ, Castanheira M, Sader HS, Jones RN. The in vitro evaluation of solithromycin (CEM-101) against pathogens isolated in the United States and Europe (2009). J Infect. 2010;61(6):476-483.

39. Jensen JS, Fernandes P, Unemo M. In vitro activity of the new fluoroketolide solithromycin (CEM-101) against macrolide-resistant and susceptible Mycoplasma genitalium. Antimicrob Agents Chemother. 2014;58(6):3151-3156.

40. Mallegol J, Fernandes P, Melano RG, Guyard C. Antimicrobial activity of solithromycin against clinical isolates of legionella pneumophila serogroup 1. Antimicrob Agents Chemother. 2014;58(2):909-915.

41. Furfaro LL, Spiller OB, Keelan JA, Payne MS. In vitro activity of solithromycin and its metabolites, CEM-214 and N-acetyl-CEM-101, against 100 clinical Ureaplasma spp. isolates compared with azithromycin. Int J Antimicrob Agents. 2015;46(3):319-324.

42. Hardy DJ, Vicino D, Fernandes P. In vitro activity of solithromycin against Bordetella pertussis, an emerging respiratory pathogen. Antimicrob Agents Chemother. 2016;60(12):7043-7045.

43. Weintraub A, Rashid MU, Nord CE. In-vitro activity of solithromycin against anaerobic bacteria from the normal intestinal microbiota. Anaerobe. 2016;42:119-122.

44. Jamieson BD, Ciric S, Fernandes P. Safety and pharmacokinetics of solithromycin in subjects with hepatic impairment. Antimicrob Agents Chemother. 2015;59(8):4379-4386.
45. Abduljalil K, Kinzig M, Bulitta J, et al. Modeling the autoinhibition of clarithromycin metabolism during repeated oral administration. Antimicrob Agents Chemother. 2009;53(7):2892-2901.

46. Still JG, Schranz J, Degenhardt TP, et al. Pharmacokinetics of solithromycin (CEM-101) after single or multiple oral doses and effects of food on single-dose bioavailability in healthy adult subjects. Antimicrob Agents Chemother. 2011;55(5):1997-2003.

47. Rodvold KA, Gotfried MH, Still JG, Clark K, Fernandes P. Comparison of plasma, epithelial lining fluid, and alveolar macrophage concentrations of solithromycin (CEM-101) in healthy adult subjects. Antimicrob Agents Chemother. 2012;56(10):5076-5081.

48. Darpo B, Sager PT, Fernandes P, et al. Solithromycin, a novel macrolide, does not prolong cardiac repolarization: a randomized, three-way crossover study in healthy subjects. J Antimicrob Chemother. 2017;72(2): 515-521.

49. Gonzalez D, Palazzi DL, Bhattacharya-Mithal L, et al. Solithromycin pharmacokinetics in plasma and dried blood spots and safety in adolescents. Antimicrob Agents Chemother. 2016;60(4):2572-2576.

50. Compra, Inc. Cempra receives complete response letter for solithromycin NDAs. Available from: http://investor.cempra.com/releasedetail.cfm?ReleaseID=1005708. Published 2016. Accessed January 4, 2017.
Drug Design, Development and Therapy

\section{Publish your work in this journal}

Drug Design, Development and Therapy is an international, peerreviewed open-access journal that spans the spectrum of drug design and development through to clinical applications. Clinical outcomes, patient safety, and programs for the development and effective, safe, and sustained use of medicines are the features of the journal, which

\section{Dovepress}

has also been accepted for indexing on PubMed Central. The manuscript management system is completely online and includes a very quick and fair peer-review system, which is all easy to use. Visit http://www.dovepress.com/testimonials.php to read real quotes from published authors.

Submit your manuscript here: http://www.dovepress.com/drug-design-development-and-therapy-journal 